\title{
Increasing children's fruit and vegetable consumption: distribution or a multicomponent programme?
}

\author{
Evelien Reinaerts ${ }^{1, *}$, Jascha de Nooijer ${ }^{1}$, Math Candel $^{2}$ and Nanne de Vries ${ }^{1}$ \\ 'Department of Health Promotion and Health Education, Universiteit Maastricht, PO Box 616, 6200 MD Maastricht, \\ The Netherlands: ${ }^{2}$ Department of Methodology and Statistics, Universiteit Maastricht, Maastricht, The Netherlands
}

Submitted 11 April 2006: Accepted 21 November 2006: First published online 22 February 2007

\begin{abstract}
Objective: To measure the effects of two school-based interventions on children's intake of fruit and vegetables (F\&V).

Design and methods: A total of six primary schools were randomly assigned to (1) a free $\mathrm{F} \& \mathrm{~V}$ distribution programme, or (2) a multicomponent programme, consisting of a classroom curriculum and parental involvement. The two interventions were evaluated on their effects and compared with six control schools in a pre-test-posttest design. Two methods were used for dietary assessment: a pre-structured food recall and a food-frequency questionnaire including only $\mathrm{F} \& \mathrm{~V}$.

Subjects: A total of 939 parents of children aged 4-12 years filled out the questionnaire at both pre-test and post-test. The response rate was 54\%.

Results: Multilevel analyses showed that both programmes were equally effective in increasing children's fruit consumption by 0.2 portions per day. The free F\&V distribution increased vegetable intake among non-native children and the oldest age group, and the multicomponent programme among the oldest children and girls. The distribution also caused an increased $24 \mathrm{~h}$ fruit, juice and vegetable intake among the youngest and the oldest age groups, and the multicomponent programme among all children.

Conclusion: The results of this study indicate that both interventions were shown to be effective for different subgroups regarding age, gender and ethnicity. When comparing both interventions, the distribution programme was shown to be more effective, especially in increasing vegetable consumption. An important next step will be to investigate which intervention has the greatest potential to be implemented in primary schools.
\end{abstract}

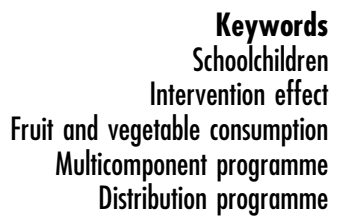

Keywords

Schoolchildren

getable consumption

Distribution programme
Substantial evidence shows that higher intake levels of fruit and vegetables $(\mathrm{F} \& \mathrm{~V})$ are associated with lower rates of cancers, cardiovascular diseases and several other diseases ${ }^{1}$. Current Dutch guidelines recommend that children should eat at least two servings of fruit and $200 \mathrm{~g}$ of vegetables a day ${ }^{2}$. Like most European children ${ }^{3}$, Dutch children have lower F\&V intake than recommended. According to the latest Dutch Food Consumption Survey, children aged 4-12 years consume on average about $70 \mathrm{~g}$ of vegetables and less than one serving of fruit daily $^{2}$. Considering that dietary habits such as F\&V consumption have been shown to persist throughout life ${ }^{4,5}$, attempts to increase children's F\&V consumption could be more efficient than interventions aimed at adults who have already developed a habit of low consumption patterns ${ }^{6}$.

From previous reviews, it can be concluded that the majority of programmes aimed at primary-school children have been classroom-based and multicomponent in nature. Most were implemented in the $\mathrm{USA}^{7-10}$. These reviews indicate that the majority of these interventions lead to increased consumption at least on the short term. Reported effects ranged from 0.14 to 0.99 servings per day higher intake in the intervention groups at follow-up ${ }^{9,10}$. Studies that incorporated an environmental factor, such as making F\&V available at school, used a multicomponent design so that the independent contribution of, for example, availability to the effectiveness of the study could not be determined. The review of French and Stables identified only three solely environmental interventions, and only one of these attempted to change the $F \& V$ consumption of children by only distributing $F \& V$ at schools $^{8}$. This paid F\&V subscription scheme provided children aged 6-10 years with one piece of fruit or vegetables per day and was implemented in four schools. Three schools in Denmark served as controls. It resulted in an increased fruit intake after 5 weeks of 0.4 pieces among subscribing children, and of 0.3 pieces among 
non-subscribing children. The beneficial effect for nonsubscribers was interpreted as an unintentional effect of stimulating parents of non-subscribers to supply their children with fruit. Contrary to the non-subscribers, the subscribers did not increase their total F\&V intake, indicating that $\mathrm{F} \& \mathrm{~V}$ consumption at school led to less consumption later in the day ${ }^{11}$. This could be the result of parents reducing the amount of F\&V they give their child normally at home. Recently, a similar Norwegian subscription scheme has been implemented and shown to be effective. This programme consisted of three conditions: a free subscription implemented in nine schools; a paid subscription implemented in nine schools; 20 schools served as the control condition receiving no fruit. After 1 year, the free fruit subscription showed a net effect of 0.9 portions during school time and 1.0 portion during the whole day. Furthermore, the results showed that at followup, the subscription programme caused differences between the free fruit group, the paid fruit group and the control group in $\mathrm{F} \& \mathrm{~V}$ intake during school time (mean intakes were 1.1, 0.4 and 0.2 portions, respectively). For $\mathrm{F} \& \mathrm{~V}$ intake all day, the free fruit group differed from the paid and control group $(2.4,1.8 \text { and } 1.8 \text {, respectively })^{12}$.

When developing school-based interventions, health promotion planners encounter the problem that motivating schools to participate in health-promoting activities has become very difficult. Reasons for refusal are mostly time constraints in the classroom and limited resources at school. More and more schools are held responsible for a growing number of health-related issues and are swamped with imposed or voluntary initiatives to improve the health of their students. Thus, it seems important to gain more insight into the effects of school-based interventions that require minimal classroom or teacher time, such as F\&V distribution at school. Moreover, we examined differences in effects between a programme that solely distributed $\mathrm{F} \& \mathrm{~V}$ at school and a programme that focused on motivating parents and children to bring F\&V to school, without making F\&V available at school. Furthermore, most multicomponent school-based programmes to increase $F \& V$ intake of children have been aimed at 4th or 5 th graders. In this study, we wanted to focus on the effects of programmes that involve all children at primary school.

The present study tests the effects on F\&V intake of a free $F \& V$ distribution and a multicomponent curriculum, compared with a control group, in a field study with a pretest and a 1-year follow-up post-test.

\section{Methods}

\section{Study design}

Schools were recruited by the Regional Health Service, which invited every school in the middle region of the province of Limburg, that had at least 200 students $(n=28)$.
Six primary schools (21\%) accepted the invitation to participate in the study. These schools were paired based on ethnic composition because the proportion of foreign students can differ substantially among primary schools. Of each pair, one school was randomly assigned to the distribution condition ( \pm 690 children) and one to the multicomponent condition ( \pm 648 children), resulting in two intervention groups each consisting of three schools. Six control schools ( \pm 1168 children) were identified in the northern region of the province of Limburg, matched on ethnicity and school size. All children in the intervention schools were offered one of the two interventions, and children in the control schools received the curriculum programme after the study period. The effects of the intervention were examined by assessing $F \& V$ intake 2 weeks before the start of the interventions (T0; October 2004) and again at the end of the school year (T1; June 2005).

In The Netherlands, children can go to primary school when they reach the age of 4 years, but when they are 5 years old it is compulsory. The first two levels (group 1 and 2) are kindergarten. When the children leave group 8 , they go to secondary school.

Both interventions were delivered to all primary-school children between October 2004 and the beginning of July 2005. Informed consent was acquired from parents prior to the study. Children's F\&V consumption was measured through a food-frequency questionnaire (FFQ) and a pre-structured food recall that all children took home to be completed by one of their parents.

\section{Interventions}

In an attempt to increase the F\&V consumption among Dutch schoolchildren, the Regional Health Service Noorden Midden Limburg and the Universiteit Maastricht cooperated in the development of two different interventions. These were developed according to the intervention mapping protocol, a stepwise approach to ensure systematic evidence-based and theory-driven development and implementation of health-promoting interventions $^{13}$, that has proved useful in the development of programmes aimed at improving $F \& V$ intake in children $^{14,15}$. The interventions were based on two programme objectives: (1) increasing children's daily F\&V consumption; and (2) creating an environment (at home and at school) that supports children's F\&V consumption.

The first intervention consisted of free F\&V distribution at school and aimed at creating a daily routine by incorporating a recurring moment at which children ate the distributed F\&V together. By daily exposure to $F \& V$, children learn to like the taste of F\&V and, furthermore, they become each other's peer models. Every school day, all children were provided with one serving of fruit (twice a week), fruit juice (once a week) or raw vegetables (twice a week). The distributor ensured a large variety of F\&V during the intervention year and ensured that the same 
kind of F\&V was not served within 1 week. The distribution was delivered twice a week, ready-to-eat and in a separate box for each class. The boxes were brought to the classrooms by a pupil or school employee, and the F\&V were handed out to the children during the morning break. Children stayed in their classroom to eat the $\mathrm{F} \& \mathrm{~V}$ together with their teacher.

The second intervention was a multicomponent schoolbased programme that consisted of a classroom curriculum and parental involvement. Children received a lunchbox that was especially designed to bring F\&V to school undamaged. Classroom activities were developed in cooperation with school teachers and were adapted to the children's age, resulting in three different programmes: one for pre-schoolers (aged 4-5 years; further referred to as age group I); one for first, second and third graders (age group II); and one for children of the fourth, fifth and sixth grade (age group III) (Table 1). Every 2 months, new activities were distributed among the teachers. By use of recurrent newsletters and homework activities taken home by the children, we tried to motivate parents to create a home environment that facilitates F\&V consumption. Furthermore, posters with the project mascots were displayed at local supermarkets, serving as an environmental component aimed at reminding parents to buy $\mathrm{F} \& \mathrm{~V}$ for their children.

\section{Measurements}

To assess F\&V, the parents of all children completed intake survey questionnaires. These included a pre-structured food recall, an FFQ, demographic questions and potential correlates of the children's F\&V intake, assessed separately for fruit and for vegetable consumption.

Demographics of the children included age, sex and ethnicity. Asking for the country of birth of both parents assessed ethnicity of the children. Children were classified as 'native' when both parents had been born in The Netherlands and as 'non-native' when one or both parents had been born outside The Netherlands, based on the definition used by Statistics Netherlands ${ }^{16}$.

The pre-structured 24-hour food recall assessed the number of times children consumed food (including fruit or vegetables) the previous day and aimed to focus parents on the total food intake of the day before and not only F\&V. The recall consisted of 16 items, for example 'Did your child eat fruit as a snack between meals' or 'a slice of bread with his/her breakfast'? Parents could indicate whether or not their child consumed the specific item the day before. However, only the information on fruit, juice and vegetable intake ( $24 \mathrm{~h} \mathrm{FJV}$ ) was included in the analysis. In The Netherlands, no school meals are typically offered. Most children go home for lunch or bring their own sandwiches to eat at school. Therefore, parents should know what their child consumes during school time.
Another measurement of F\&V consumption was the FFQ. Two questions were used to assess children's consumption of whole fruit: 'How many days per week does your child eat fruit?' (1-7) and 'How many portions of fruit does your child eat on a day that he or she consumes fruit?' ranging from ' $1 / 2$ portion a day' to ' 3 portions a day or more' on a 6-point scale. The average consumption of whole fruit (in portions per day) was calculated by multiplying both questions and dividing the result by 7 .

The frequency of vegetable intake was measured by three questions, asking how many times per week the child eats (1) cooked or baked vegetables for dinner (including mixed dishes); (2) mixed dishes such as macaroni; and (3) extra salad, such as lettuce, tomato or other raw vegetables. The number of days that the children consumed cooked vegetables was calculated by subtracting (2) mixed dishes from (1) cooked or baked vegetables including mixed dishes. Portion size was assessed using photographs of plates filled with different amounts of cooked vegetables $(25,50,100$ and $150 \mathrm{~g}$ ) or mixed dishes $(75,150,300$ and $450 \mathrm{~g})$. Parents had to select the photograph that best represented the amount of food that their child usually consumes. According to The Netherlands Nutrition Centre, on average, 33\% of a mixed dish consists of vegetables. The amount of extra salad or raw vegetables was calculated by multiplying frequency per week by $35 \mathrm{~g}$ (the weight of a small bowl of salad). Finally, the average consumption of vegetables in grams per day was computed as [(the number of days that the children consumed cooked vegetables $\times$ portion size) + (the number of days children ate mixed dishes $\times 0.33 \times$ portion size) + (the number of days children ate extra salad or raw vegetables $\times 35 \mathrm{~g}$ )] $/ 7$ days. To assess daily intake of 'snack vegetables', we asked how many times per week the child eats vegetables separately as a snack between meals (such as a tomato or a piece of cucumber) or as part of breakfast or lunch (1-7), and we divided this by 7 .

The FFQ method was used in a similar Dutch project and was based on the Pro-children questionnaire that was validated by Haraldsdóttir ${ }^{17,18}$.

\section{Statistical analyses}

Data analyses included descriptive statistics of the demographic factors and F\&V consumption. Attrition was studied by means of multilevel logistic regression analysis with attrition as the dependent variable and child's age, sex and ethnicity, child's F\&V consumption at baseline (average and $24 \mathrm{~h}$ ) and condition as predictors. $\chi^{2}$ tests and $F$-tests were used to compare baseline characteristics between study groups. Data on F\&V consumption that were gathered using the FFQ measures were not distributed normally. Therefore, the data were square root transformed to improve normality. 
Table 1 Description of the classroom activities of the multicomponent programme

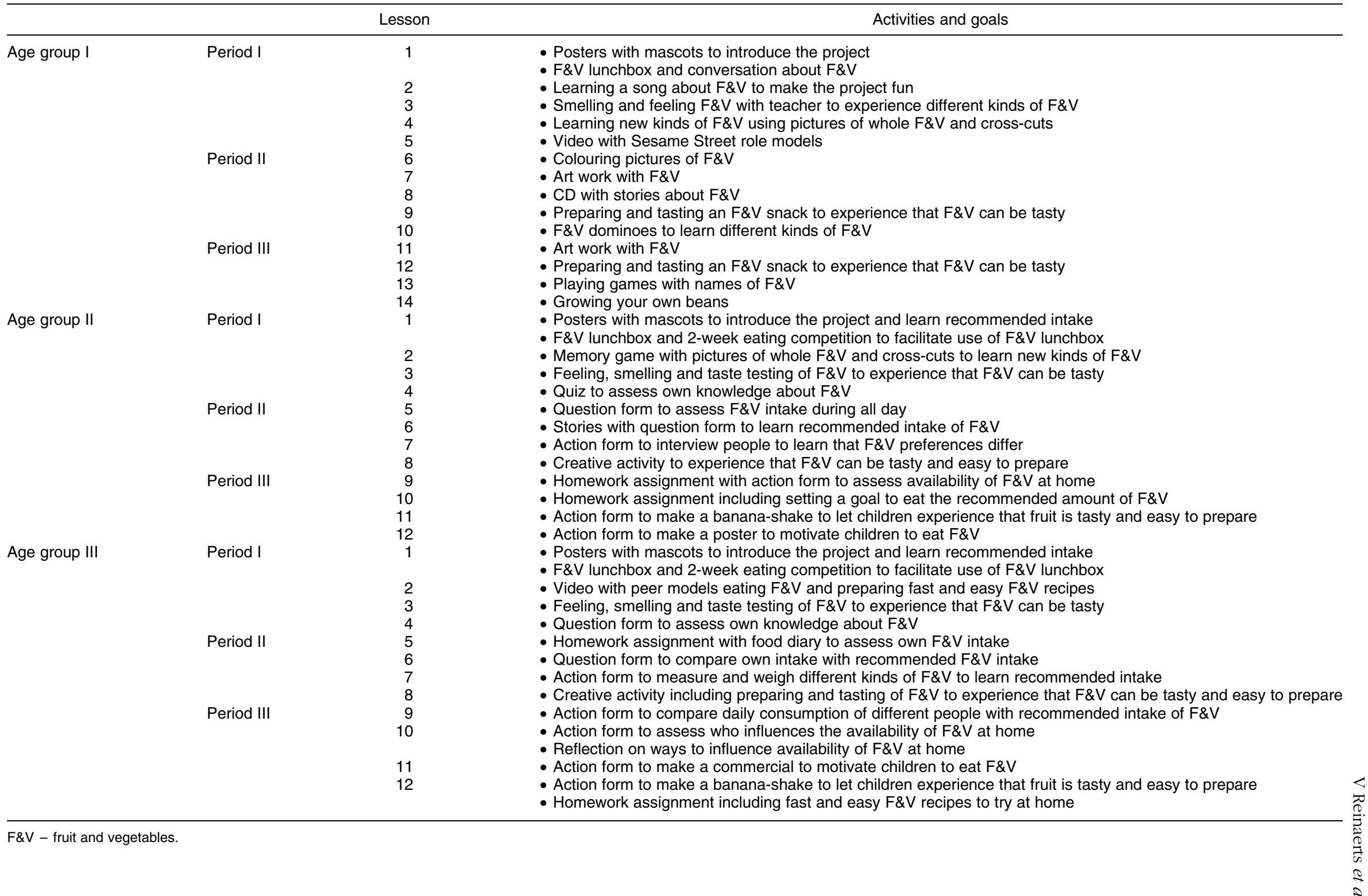


Since we had a nested sampling design (pupils within classes within schools), multilevel analyses ${ }^{19}$ were conducted. By extending the fixed regression model with a random school effect and a random class effect, the intraclass correlation was taken into account ${ }^{20}$. Four sets of multilevel models were analysed to test the influence of both interventions on: (1) average fruit consumption (fruit consumption in portions per day); (2) average vegetable consumption (vegetable consumption at dinner in grams per day); (3) vegetable snack consumption (frequency of vegetable snack consumption in times per day); and (4) $24 \mathrm{~h} \mathrm{FJV} \mathrm{consumption} \mathrm{(frequency} \mathrm{of} \mathrm{FJV}$ consumption during the previous day in times per day).

All analyses included a dummy variable for the distribution and the multicomponent intervention group as main independent variables (the control group was taken as a reference), controlling for child's ethnicity, gender, age group and baseline consumption level. These analyses were repeated with the distribution group as a reference to check for differences in effect between the two interventions. We tested for interaction effects between condition and gender, ethnicity and age group. If necessary, these were followed by subgroup analyses. All analyses were done according to a 'top-down' procedure, i.e. starting with the most elaborate model and leaving out successively the least significant and nonsignificant effects.

To indicate effect size of the interventions, the net effect was used, being equal to the change in fruit and vegetable intake between the intervention and control group. Thus, net effect $=$ (follow-up intake intervention $_{- \text {baseline }}$ intake $\left._{\text {intervention }}\right)$ - (follow-up intake control $_{\text {- baseline }}$ intake $_{\text {control }}$ ).

\section{Results}

\section{Participants}

At baseline, a total of 1730 (68\%) parents filled out the questionnaire for their child. Of these parents, 939 (54\%) also filled out the questionnaire at follow-up, equally distributed across all three groups.

Attrition analyses revealed that parents of non-native children dropped out more often than parents of Dutch children (52 v. 42\%, $P<0.001$ ). No further differences were found between drop-outs and participants.

\section{Baseline characteristics of the children}

The average age of the children was 9 years (standard deviation $(\mathrm{SD})=2.3$ ), ranging from 5 to 14 years, and $51.5 \%$ ( $n=482$ ) were girls. Before conducting multilevel analyses to examine the effectiveness of the interventions, preliminary analyses were done to determine whether children began the interventions with differences in age, sex, ethnicity and baseline consumption levels. There were no significant differences between the three intervention groups in demographic variables at baseline, except for ethnicity (control vs. multicomponent vs. distribution: 14 vs. 12 vs. $50 \%$ non-native; $P<0.001$ ). This difference probably occurred due to children who enrolled in the schools in the period between the assignment of the interventions to the schools and the start of the interventions, approximately 4 months including the summer holiday. Regarding F\&V intake, children in the distribution group consumed $24 \mathrm{~h}$ FJV more often at baseline than children in the multicomponent $(P<0.001)$ and control group $(P<0.001)$. They also consumed vegetable snacks more often than children in the control group $(P<0.01)$.

\section{Effects}

Average fruit, vegetable and vegetable snack consumption and $24 \mathrm{~h}$ FJV consumption at baseline and follow-up are presented as medians with interquartile range and as means with SDs separately for the distribution programme (Table 2) and the multicomponent programme (Table 3). Furthermore, in these tables, the effects of the interventions when evaluated against the control group are reported.

Both the free distribution and the multicomponent programme were effective in increasing children's average fruit consumption (Tables 2 and 3). Both increased consumption with a net effect of 0.2 portions $(+15 \%$, net effect compared with baseline intake of the intervention group; $P<0.001$ ) per day including weekend days. For all other outcome measures, our results showed different effects of the interventions for different subgroups.

Vegetable intake at dinner was increased only by the distribution programme for age group III $(+22 \%$; $P<0.01)$ and for non-native children $(+32 \% ; P<0.01)$. Regarding vegetable snack intake, the distribution programme was effective for age group III $(+33 \%$; $P<0.01)$ and the multicomponent programme for age group II $(+50 \% ; P<0.05)$ and for girls $(+50 \% ; P<0.01)$.

Effects on $24 \mathrm{~h}$ FJV consumption (on school days) were found among the children who received the multicomponent programme, but these effects differed by ethnicity; native children increased their consumption by 0.2 times per day $(+8 \% ; P<0.05)$ and non-native children by 1.6 times per day $(+60 \% ; P<0.01)$. The distribution programme also increased the $24 \mathrm{~h}$ FJV consumption, for age group I by 0.1 times per day $(+4 \% ; P<0.05)$ and for age group III by 0.5 times per day $(+15 \% ; P<0.01)$.

In order to identify the most effective intervention, we compared the distribution and the multicomponent programme by repeating all multilevel analyses, using the distribution programme as reference. If previous effect analyses revealed a significant subgroup effect for one of the interventions, we compared both interventions for that particular subgroup (Table 4).

Our results showed that both interventions were equally effective in increasing fruit consumption. The distribution 


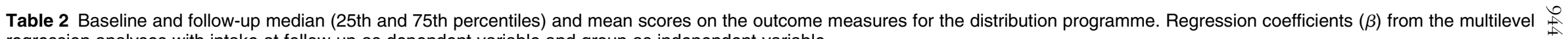
regression analyses with intake at follow-up as dependent variable and group as independent variable

\begin{tabular}{|c|c|c|c|c|c|c|c|}
\hline & & \multicolumn{2}{|c|}{ Baseline median (P25, P75); mean (SD) } & \multicolumn{2}{|c|}{ Follow-up median (P25, P75); mean (SD) } & \multirow[b]{2}{*}{$\beta$} & \multirow[b]{2}{*}{ Net effect } \\
\hline & & DI & C & DI & C & & \\
\hline $\begin{array}{l}\text { Fruit } \\
\text { (portions per day) }\end{array}$ & & $n=274 ; 1.1(1.1,1.7) ; 1.3(0.9)$ & $n=439 ; 1.1(0.7,1.7) ; 1.2(0.7)$ & $n=270 ; 1.4(0.9,2.1) ; 1.5(0.9)$ & $n=439 ; 1.1(0.7,1.7) ; 1.2(0.7)$ & $0.10^{\star \star \star}$ & 0.2 \\
\hline $\begin{array}{l}\text { Vegetables } \\
\text { grams per day }\end{array}$ & $\begin{array}{l}\text { Age group I } \\
\text { Age group II } \\
\text { Age group III } \\
\text { Native } \\
\text { Non-native }\end{array}$ & $\begin{array}{l}n=49 ; 52(36,69) ; 52(25) \\
n=106 ; 57(39,73) ; 59(28) \\
n=96 ; 60(36,90) ; 65(36) \\
n=122 ; 55(43,71) ; 58(26) \\
n=115 ; 61(34,85) ; 63(35)\end{array}$ & $\begin{array}{l}n=73 ; 49(33,60) ; 49(23) \\
n=157 ; 59(40,78) ; 62(29) \\
n=191 ; 62(48,86) ; 66(29) \\
n=354 ; 58(41,74) ; 60(27) \\
n=54 ; 58(38,96) ; 67(39)\end{array}$ & $\begin{array}{l}n=52 ; 53(36,67) ; 53(23) \\
n=108 ; 55(43,77) ; 63(30) \\
n=94 ; 70(51,106) ; 78(38) \\
n=125 ; 61(40,75) ; 61(28) \\
n=117 ; 61(46,96) ; 71(37)\end{array}$ & $\begin{array}{l}n=73 ; 50(36,62) ; 55(27) \\
n=153 ; 53(35,71) ; 56(27) \\
n=180 ; 58(46,81) ; 65(30) \\
n=341 ; 55(41,74) ; 60(28) \\
n=53 ; 49(33,65) ; 55(34)\end{array}$ & $\begin{array}{l}-0.31 \\
0.35 \\
1.11^{\star *} \\
0.23 \\
1.10^{* \star}\end{array}$ & $\begin{array}{r}-5 \\
10 \\
14 \\
3 \\
20\end{array}$ \\
\hline $\begin{array}{l}\text { Vegetable snack } \\
\text { (times per day) }\end{array}$ & $\begin{array}{l}\text { Age group I } \\
\text { Age group II } \\
\text { Age group III }\end{array}$ & $\begin{array}{l}n=54 ; 0.3(0.0,0.4) ; 0.3(0.3) \\
n=108 ; 0.3(0.0,0.6) ; 0.3(0.3) \\
n=97 ; 0.3(0.1,0.4) ; 0.3(0.3)\end{array}$ & $\begin{array}{l}n=76 ; 0.3(0.0,0.4) ; 0.3(0.3) \\
n=164 ; 0.3(0.0,0.4) ; 0.3(0.2) \\
n=197 ; 0.1(0.0,0.4) ; 0.2(0.2)\end{array}$ & $\begin{array}{l}n=53 ; 0.3(0.1,0.4) ; 0.3(0.3) \\
n=108 ; 0.3(0.1,0.4) ; 0.3(0.3) \\
n=97 ; 0.4(0.1,0.6) ; 0.4(0.3)\end{array}$ & $\begin{array}{l}n=77 ; 0.3(0.1,0.6) ; 0.3(0.3) \\
n=162 ; 0.3(0.1,0.4) ; 0.3(0.3) \\
n=192 ; 0.1(0.1,0.4) ; 0.2(0.2)\end{array}$ & $\begin{array}{l}-0.02 \\
0.03 \\
0.10^{* *}\end{array}$ & $\begin{array}{l}0.0 \\
0.0 \\
0.1\end{array}$ \\
\hline $\begin{array}{l}\text { 24 h FJV } \\
\text { (times per day) }\end{array}$ & $\begin{array}{l}\text { Age group I } \\
\text { Age group II } \\
\text { Age group III }\end{array}$ & $\begin{array}{l}n=36 ; 2.0(2.0,3.0) ; 2.6(1.2) \\
n=91 ; 3.0(2.0,4.0) ; 2.9(1.4) \\
n=78 ; 3.0(2.0,5.0) ; 3.4(1.7)\end{array}$ & $\begin{array}{l}n=64 ; 2.0(2.0,3.0) ; 2.4(1.3) \\
n=145 ; 2.0(2.0,3.0) ; 2.5(1.2) \\
n=178 ; 2.5(2.0,3.0) ; 2.6(1.2)\end{array}$ & $\begin{array}{l}n=41 ; 3.0(2.0,4.0) ; 3.1(1.4) \\
n=92 ; 3.0(2.0,4.0) ; 3.3(1.3) \\
n=85 ; 4.0(2.8,5.0) ; 4.0(1.7)\end{array}$ & $\begin{array}{l}n=70 ; 3.0(2.0,4.0) ; 2.8(1.2) \\
n=141 ; 3.0(2.0,3.0) ; 2.8(1.3) \\
n=165 ; 3.0(2.0,3.0) ; 2.7(1.2)\end{array}$ & $\begin{array}{l}0.50^{\star} \\
0.34 \\
0.61^{\star \star}\end{array}$ & $\begin{array}{l}0.1 \\
0.1 \\
0.5\end{array}$ \\
\hline
\end{tabular}

P25 - 25th percentile; P75 -75 th percentile; SD - standard deviation; DI - distribution programme; $\mathrm{C}$ - control group; FJV - fruit, vegetables and fruit juice.
${ }^{*} P<0.05 ;{ }^{* *} P<0.01 ;{ }^{* * *} P<0.001$.

Table 3 Baseline and follow-up median (25th and 75th percentiles) and mean scores on the outcome measures for the multicomponent programme. Regression coefficients $(\beta)$ from the multilevel regression analyses with intake at follow-up as dependent variable and group as independent variable

\begin{tabular}{|c|c|c|c|c|c|c|c|}
\hline & & \multicolumn{2}{|c|}{ Baseline median (P25, P75); mean (SD) } & \multicolumn{2}{|c|}{ Follow-up median (P25, P75); mean (SD) } & \multirow[b]{2}{*}{$\beta$} & \multirow[b]{2}{*}{ Net effec } \\
\hline & & MC & C & MC & C & & \\
\hline $\begin{array}{l}\text { Fruit } \\
\text { (portions per day) }\end{array}$ & & $n=209 ; 1.1(0.7,1.7) ; 1.3(0.8)$ & $n=439 ; 1.1(0.7,1.7) ; 1.2(0.7)$ & $n=206 ; 1.4(0.9,2.1) ; 1.5(0.8)$ & $n=439 ; 1.1(0.7,1.7) ; 1.2(0.7)$ & $0.11^{\star \star *}$ & 0.2 \\
\hline $\begin{array}{l}\text { Vegetables } \\
\text { grams per day }\end{array}$ & & $n=196 ; 53(38,68) ; 58(32)$ & $n=421 ; 58(41,75) ; 61(29)$ & $n=190 ; 52(35,74) ; 56(30)$ & $n=406 ; 55(40,74) ; 60(29)$ & -0.03 & -1 \\
\hline $\begin{array}{l}\text { Vegetable snack } \\
\text { (times per day) }\end{array}$ & $\begin{array}{l}\text { Age group I } \\
\text { Age group II } \\
\text { Age group III } \\
\text { Boys } \\
\text { Girls }\end{array}$ & $\begin{array}{l}n=49 ; 0.1(0.1,0.4) ; 0.2(0.2) \\
n=87 ; 0.1(0.0,0.3) ; 0.2(0.2) \\
n=66 ; 0.1(0.0,0.3) ; 0.2(0.2) \\
n=90 ; 0.1(0.0,0.3) ; 0.2(0.2) \\
n=112 ; 0.1(0.1,0.3) ; 0.2(0.2)\end{array}$ & $\begin{array}{l}n=76 ; 0.3(0.0,0.4) ; 0.3(0.3) \\
n=164 ; 0.3(0.0,0.4) ; 0.3(0.2) \\
n=197 ; 0.1(0.0,0.4) ; 0.2(0.2) \\
n=208 ; 0.1(0.0,0.4) ; 0.2(0.3) \\
n=226 ; 0.3(0.1,0.4) ; 0.3(0.2)\end{array}$ & $\begin{array}{l}n=53 ; 0.1(0.1,0.6) ; 0.3(0.3) \\
n=84 ; 0.3(0.1,0.4) ; 0.3(0.3) \\
n=64 ; 0.2(0.0,0.4) ; 0.3(0.3) \\
n=91 ; 0.1(0.0,0.3) ; 0.2(0.3) \\
n=110 ; 0.3(0.1,0.6) ; 0.3(0.3)\end{array}$ & $\begin{array}{l}n=77 ; 0.3(0.1,0.6) ; 0.3(0.3) \\
n=162 ; 0.3(0.1,0.4) ; 0.3(0.3) \\
n=192 ; 0.1(0.1,0.4) ; 0.2(0.2) \\
n=207 ; 0.3(0.0,0.4) ; 0.3(0.2) \\
n=221 ; 0.3(0.1,0.4) ; 0.3(0.3)\end{array}$ & $\begin{array}{l}-0.01 \\
0.06^{\star} \\
0.03 \\
0.00 \\
0.07^{* \star}\end{array}$ & $\begin{array}{r}0.1 \\
0.1 \\
0.1 \\
-0.1 \\
0.1\end{array}$ \\
\hline $\begin{array}{l}\text { 24 h FJV } \\
\text { (times per day) }\end{array}$ & $\begin{array}{l}\text { Native } \\
\text { Non-native }\end{array}$ & $\begin{array}{l}n=168 ; 2.0(2.0,3.0) ; 2.5(1.2) \\
n=21 ; 3.0(2.0,4.0) ; 2.7(1.3)\end{array}$ & $\begin{array}{l}n=332 ; 2.0(2.0,3.0) ; 2.4(1.1) \\
n=43 ; 4.0(3.0,5.0) ; 3.8(1.5)\end{array}$ & $\begin{array}{l}n=160 ; 3.0(2.0,4.0) ; 3.0(1.2) \\
n=19 ; 4.0(3.0,5.0) ; 3.8(1.4)\end{array}$ & $\begin{array}{l}n=323 ; 3.0(2.0,3.0) ; 2.7(1.2) \\
n=41 ; 3.0(2.0,5.0) ; 3.3(1.8)\end{array}$ & $\begin{array}{l}0.24^{*} \\
1.30^{* \star}\end{array}$ & $\begin{array}{l}0.2 \\
1.6\end{array}$ \\
\hline
\end{tabular}


Table 4 Regression coefficients $(\beta)$ from the multilevel regression analyses comparing the distribution programme vs. control group, multicomponent programme vs. control group, and multicomponent programme vs. distribution programme

\begin{tabular}{|c|c|c|c|c|c|}
\hline & & DI vs. C & MC vs. C & MC vs. DI & $\begin{array}{c}\text { Pairwise } \\
\text { comparisons }\end{array}$ \\
\hline Fruit (portions per day) & & $0.10^{\star \star \star}$ & $0.11^{\star \star \star}$ & 0.01 & $\mathrm{DI}, \mathrm{MC}>\mathrm{C}$ \\
\hline \multirow[t]{5}{*}{ Vegetables (grams per day) } & Age group I & -0.31 & -0.41 & -0.10 & \\
\hline & Age group II & 0.35 & 0.22 & -0.13 & NS \\
\hline & Age group III & $10.11^{*}$ & -0.32 & $-10.34^{\star \star \star}$ & $\mathrm{DI}>\mathrm{MC}, \mathrm{C}$ \\
\hline & Native & 0.23 & -0.04 & -0.26 & \\
\hline & Non-native & $10.10^{\star \star}$ & -0.32 & $-10.41^{\star \star}$ & $\mathrm{DI}>\mathrm{MC}, \mathrm{C}$ \\
\hline \multirow[t]{5}{*}{ Vegetable snack (times per day) } & Age group I & -0.02 & -0.01 & 0.01 & NS \\
\hline & Age group II & 0.03 & $0.06^{*}$ & 0.04 & $\mathrm{MC}>\mathrm{C}$ \\
\hline & Age group III & $0.10^{\star *}$ & 0.03 & $-0.08^{\star}$ & $\mathrm{DI}>\mathrm{MC}, \mathrm{C}$ \\
\hline & Boys & $0.06^{\star}$ & 0.00 & $-0.06^{\star}$ & $\mathrm{DI}>\mathrm{MC}, \mathrm{C}$ \\
\hline & Girls & 0.03 & $0.07^{\star \star}$ & 0.04 & $M C>C$ \\
\hline \multirow[t]{5}{*}{ 24 h FJV (times per day) } & Age group I & $0.50^{*}$ & 0.17 & -0.33 & $\mathrm{DI}>\mathrm{C}$ \\
\hline & Age group II & 0.34 & $0.40^{*}$ & 0.06 & $\mathrm{MC}>\mathrm{C}$ \\
\hline & Age group III & $0.61^{\star \star}$ & $0.39^{*}$ & -0.22 & $\mathrm{DI}, \mathrm{MC}>\mathrm{C}$ \\
\hline & Native & $0.38^{* *}$ & $0.24^{*}$ & -0.14 & $\mathrm{DI}, \mathrm{MC}>\mathrm{C}$ \\
\hline & Non-native & $0.81^{\star \star}$ & $10.30^{\star \star}$ & 0.49 & $\mathrm{DI}, \mathrm{MC}>\mathrm{C}$ \\
\hline
\end{tabular}

DI - distribution programme; C - control group; MC - multicomponent programme; FJV - fruit, juice and vegetables; NS - no significant difference.

${ }^{\star} P<0.05 ;{ }^{* *} P<0.01 ;{ }^{* * *} P<0.001$.

programme was more effective than the multicomponent programme in increasing vegetable intake at dinner for age group III $(\beta=-1.34 ; P<0.001)$ and for non-native children $(\beta=-1.41 ; \quad P<0.01)$, and in increasing vegetable snack intake for age group III $(\beta=-0.08$; $P<0.05)$ and boys $(\beta=-0.06 ; P<0.05)$. Regarding $24 \mathrm{~h}$ FJV intake, both programmes were shown to be equally effective for all age groups, and for native and non-native children.

\section{Discussion}

The present study was an effect evaluation of two Dutch school-based intervention programmes aimed at increasing the $\mathrm{F} \& \mathrm{~V}$ consumption of primary-school children. Results indicate that both the multicomponent programme and the $F \& V$ distribution were equally effective in increasing children's fruit consumption. Regarding the other outcome measures, we conclude that both programmes differ in effectiveness for different subgroups. The distribution programme seems especially effective among the oldest children (age group III), because these children benefited from the distribution on all outcome measures. The programme even increased vegetable intake during dinner for the oldest children and for non-native children. This effect is particularly promising since vegetables were only distributed at school and no further efforts were made to increase consumption at home. A possible explanation for this effect is that children increased their liking for vegetables by repeated exposure at school. This effect was shown in a study by Wardle et al. where children showed an increased liking for a specific vegetable after repeated exposure to this vegetable for only 2 weeks ${ }^{21}$.
Although this additional effect on vegetable intake during dinner was not shown for the multicomponent programme, the latter was effective in increasing vegetable snack consumption among children of the first to third grade (age group II) and for girls, unlike the distribution programme. Furthermore, the multicomponent programme increased $24 \mathrm{~h}$ FJV consumption for all children, but a larger effect was shown for non-native children.

It has to be noted that in some situations the analyses showed a different effectiveness for the interventions; however, this difference could not be detected when we compared both interventions against each other. These seemingly contradictory results may occur when the difference between the control and an intervention group are large enough to reach significance, while at the same time the differences between the two intervention groups are not large enough to become significant.

The increase in fruit consumption by the multicomponent intervention is comparable with similar multicomponent programmes put in place in primary schools ${ }^{7,9,10}$. Our results showed that vegetable consumption is more difficult to change. This was also concluded in a review by Miller and Stafford ${ }^{22}$ and could be explained by the fact that children usually accept fruit more than vegetables $^{7,23}$, perhaps because of its sweetness and greater energy density ${ }^{24}$.

Also the effects of the distribution programme are comparable with the findings of similar studies ${ }^{11,12}$. Bere et al. ${ }^{12}$ showed that the total $\mathrm{F} \& \mathrm{~V}$ intake (portions per day) increased by a daily free subscription programme in 7 th grade children. The study of Eriksen et al ${ }^{11}$ compared a paid subscription with no subscription among children up to grade 3 and found effects on $24 \mathrm{~h}$ fruit consumption 
after 5 weeks. Surprisingly, non-subscribing classmates also increased their fruit intake.

In contrast to the study of Bere et al. ${ }^{12}$, we also analysed the effects of the programmes separately for fruit and vegetables. As we did not know exactly how many children received a portion of fruit and how many received vegetables on the day their parents filled out the survey, we also chose to use an FFQ measure that computed the daily consumption based on a week. By including weekend days in this measure, the effects of the distribution on a school day could even be underestimated, since F\&V were only distributed during school days. Our confidence in the effectiveness of the interventions is bolstered since this more 'robust' frequency measure found effects for both interventions, in contrast to the study of Eriksen et al. ${ }^{11}$.

In contrast ot most school-based interventions aimed at increasing F\&V intake, this study focused on all children in the primary schools. This means that similar activities, although adapted to the age of the children, were developed for all grades. Furthermore, the whole school adopted the intervention and thereby may have made visible to the children and the parents that consuming F\&V at school is the social norm. We think that this approach has an important added value over interventions that focus solely on a selection of primary-school children.

As we were interested in the effects on all children (aged 4-12 years), we had to use self-reported data from parents, since the youngest children were not able to fill in questionnaires. The measures we used, although similar to those used in other intervention studies, were not validated among the target population. This should be regarded as a limitation of the study.

A second limitation is the randomisation procedure. Schools were not randomly assigned to the intervention or control groups, but were matched based on school size and ethnicity. Baseline analyses, however, showed that schools were comparable except for ethnicity and baseline consumption levels. These were therefore included as covariates in all analyses.

Furthermore, only $21 \%$ of the schools decided to participate in the study. This low participation rate might be caused by an overwhelming number of requests for primary schools to take part in all kinds of extracurricular initiatives, and it may have led to the selection of schools especially interested in health-related activities. This could limit the generalisability of the study results.

Our aim was to conclude this paper with a recommendation for the 'best' intervention (either the distribution or the multicomponent programme) for increasing children's F\&V consumption at primary schools. Our results showed that we cannot simply conclude that one of the two was the most effective for all children, because both interventions showed different effects on children of different age, gender and ethnicity. However, when comparing both interventions, we must conclude that distributing F\&V was more effective: beside an increase in fruit and $24 \mathrm{~h}$ FJV consumption, the distribution programme was also effective in increasing vegetable consumption for different subgroups.

Although both interventions resulted in significant increases in F\&V consumption, these are probably not enough to reduce disease risks. The number of children who meet the Dutch standards after these relative small increases will remain low. In terms of public health effects, more efforts are needed. Our interventions, however, were relatively easy to implement (compatible with normal school procedures) and not very expensive.

Since we now know that both strategies are more or less effective, a combination of both interventions could also be considered. If children are motivated (by a multicomponent programme) to eat more F\&V and these are made available at school every day, an opportunity is created for the children to put their intention into practice. This strategy might close the gap between intention and behaviour, which might result in an even larger effect on F\&V intake.

Unfortunately, effectiveness is not the only consideration that has to be taken into account. When resources are limited, other factors also become important. For example, the multicomponent programme is relatively low in cost, but takes a lot of classroom time, and is labourintensive to put into practice ${ }^{7,25-27}$. Also a lack of adoption or (loyal) implementation of curricula due to time constraints has been reported ${ }^{28}$. A free distribution, on the other hand, is easier to implement because it becomes a daily routine, but is far more expensive compared with a multicomponent programme. To discover factors that inhibit the success of these school-based programmes, it is essential to conduct an extensive process evaluation, certainly encompassing the key actors in programme delivery, the teachers.

\section{Acknowledgements}

Sources of funding: The Netherlands Organization for Health Research and Development (ZonMw) provided funding for this study as part of the Healthy Living programme (no. 4010.0014).

Authorship responsibilites: E.R. was the principal researcher, J.N. and N.V. were scientific advisors and M.C. provided statistical guidance.

Conflict of interest declaration: The authors have no conflict of interest.

\section{References}

1 World Health Organization (WHO). Diet, Nutrition and the Prevention of Chronic Diseases. WHO Technical Report Series 916. Geneva: WHO, 2002.

2 Dutch Food Consumption Survey Team. Resultaten van de Voedsel Consumptie Peiling 1997-1998 [Results of the 
Dutch Nutrition Survey 1997-1998]. The Hague: Voedingscentrum, 1998.

3 Yngve A, Wolf A, Poortvliet E, Elmadfa I, Brug J, Ehrenblad B, et al. Fruit and vegetable intake in a sample of 11-year-old children in 9 European countries: the Pro Children cross-sectional survey. Annals of Nutrition \& Metabolism 2005; 49: 236-45.

4 Lien N, Lytle LA, Klepp K-I. Stability in consumption of fruit, vegetables and sugary foods in a cohort from age 14 to age 21. Preventive Medicine 2001; 33: 217-26.

5 Kelder SH, Perry C, Klepp K-I, Lytle L. Longitudinal tracking of adolescent smoking, physical activity, and food choice behaviors. American Journal of Public Health 1994; 84: 1121-6.

6 Krebs-Smith SM, Heimendinger J, Patterson BH, Subar AF, Kessler R, Pivonka E. Psychosocial factors associated with fruit and vegetable consumption. American Journal of Health Promotion 1995; 10: 98-104.

7 Burchett $H$. Increasing fruit and vegetable consumption among British primary schoolchildren: a review. Health Education 2003; 103: 99-109.

8 French SA, Stables G. Environmental interventions to promote vegetable and fruit consumption among youth in school settings. Preventive Medicine 2003; 37: 593-610.

9 Knai C, Pomerleau J, Lock K, McKee M. Getting children to eat more fruit and vegetables: a systematic review. Preventive Medicine 2006; 42: 85-95.

10 Pomerleau J, Lock K, Knai C, McKee M. Effectiveness of Interventions and Programmes Promoting Fruit and Vegetable Intake. Geneva: World Health Organization, 2005.

11 Eriksen K, Haraldsdottir J, Pederson R, Vig Flyer H. Effect of a fruit and vegetable subscription in Danish schools. Public Health Nutrition 2003; 6: 57-63.

12 Bere E, Veierod MB, Klepp K-I. The Norwegian School Fruit Programme: evaluating paid vs. no-cost subscriptions. Preventive Medicine 2005; 41: 463-70.

13 Bartholomew LK, Parcel GS, Kok G, Gottlieb NH. Intervention Mapping. Designing Theory- and Evidence-based Health Promotion Programs. New York: McGraw Hill, 2001.

14 Perez-Rodrigo C, Wind M, Hildonen C, Bjelland M, Aranceta J, Klepp K-I, et al. The Pro Children Intervention: applying the intervention mapping protocol to develop a school-based fruit and vegetable promotion programme. Annals of Nutrition E Metabolism 2005; 49: 267-77.

15 Weber Cullen K, Bartholomew LK, Parcel GS, Kok G. Intervention mapping: use of theory and data in the development of a fruit and vegetable nutrition program for Girl Scouts. Journal of Nutrition Education 1998; 30: $188-95$.
16 Statistics Netherlands. Standard for Ethnicity (CBS). Heerlen-Voorburg: Statistics Netherlands, 2005.

17 Haraldsdóttir J, Thórsdóttir I, de Almeida MDV, Maes L, Pérez Rodrigo C, Elmadfa I, et al. Validity and reproducibility of a precoded questionnaire to assess fruit and vegetable intake in European 11- to 12-year-old schoolchildren. Annals of Nutrition \& Metabolism 2005; 49: 221-7.

18 Reinaerts EBM, De Nooijer J, Van de Kar A, De Vries NK Development of a school-based intervention to promote fruit and vegetable consumption: exploring perceptions among four- to-twelve year old children and their parents. Health Education 2006; 106: 345-56.

19 Rasbash J, Browne W, Goldstein H. A User's Guide to MLwiN Version 2.1. London: Institute of Education, University of London, 2000.

20 Snijders TAB, Bosker RJ. Multilevel Analyses. An Introduction to Basic and Advanced Multilevel Modelling. London: Sage, 1999

21 Wardle J, Cooke LJ, Leigh Gibson E, Sapochnik M, Sheiham A, Lawson M. Increasing children's acceptance of vegetables; a randomized trial of parent-led exposure. Appetite 2003; 40: $155-62$

22 Millee M, Staflord H. An Intervention Portfolio to Promote Fruit and Vegetable Consumption; Review of Interventions. Melbourne: National Public Health Partnership, 2000.

23 Baxter SD, Thompson WO. Fourth-grade children's consumption of fruit and vegetable items available as part of school lunches is closely related to preferences. Journal of Nutrition Education and Behavior 2002; 34: 166-71.

24 Gibson E, Wardle J. Energy density predicts preferences for fruit and vegetables in 4-year-old children. Appetite 2003; 41: 97-8.

25 Baranowski T, Davis M, Resnicow K, Baranowski J, Doyle C, Lin LS, et al. Gimme 5 fruit, juice and vegetables for fun and health: outcome evaluation. Health Education \& Behavior 2000; 27: 96-111.

26 Perry C, Bishop D, Taylor G, Murray D, Warren Mays R, Dudovitz B, et al. Changing fruit and vegetable consumption among children: the 5-a-day Power Plus Program in St. Paul, Minnesota. American Journal of Public Health 1998; 88 : 603-9.

27 Reynolds K, Franklin F, Binkley D, Raczynski J, Harrington $\mathrm{K}$, Kirk $\mathrm{K}$, et al. Increasing the fruit and vegetable consumption of fourth-graders: results from the High 5 Project. Preventive Medicine 2000; 30: 309-19.

28 Nicklas TA, Johnson CC, Myers L, Farris RP, Cunningham A Outcomes of a high school program to increase fruit and vegetable consumption: Gimme 5 - a fresh nutrition concept for students. Journal of School Health 1998; 68 : $248-63$ 